\title{
Inappropriate Device Material
}

National Cancer Institute

\section{Source}

National Cancer Institute. Inappropriate Device Material. NCI Thesaurus. Code $C 92065$.

Problems that occur due to the presence of a material that should not be present or part of the device. 